\title{
Pestalactams A-C: Novel Caprolactams from the Endophytic Fungus Pestalotiopsis sp.
}

Rohan A. Davis, ${ }^{\mathrm{a}, *}$ Anthony R. Carroll, ${ }^{\mathrm{a}}$ Katherine T. Andrews, ${ }^{\mathrm{a}, \mathrm{b}}$ Glen M. Boyle, ${ }^{\mathrm{b}}$ Truc Linh Tran, ${ }^{\mathrm{b}}$ Peter C. Healy, ${ }^{\mathrm{a}}$ John A. Kalaitzis, ${ }^{\mathrm{d}}$ and Roger G. Shivas ${ }^{\mathrm{e}}$

${ }^{\text {a }}$ Eskitis Institute, Griffith University, Brisbane, QLD 4111, Australia

${ }^{\mathrm{b}}$ Queensland Institute for Medical Research, Herston, Queensland, Australia, 4006; Griffith Medical Research College, a joint program of Griffith University and QIMR, Herston, Queensland, Australia

' School of Biotechnology and Biomolecular Sciences, The University of New South Wales, Sydney, NSW 2052, Australia

${ }^{\mathrm{d}}$ Queensland Primary Industries and Fisheries, Indooroopilly, QLD 4068, Australia

* Corresponding author. Tel.: +61-7-3735-6043; fax: +61-7-3735-6001. E-mail address: r.davis@griffith.edu.au (R. Davis). 


\begin{abstract}
Chemical investigations of a fermentation culture from the endophytic fungus Pestalotiopsis sp. yielded three novel caprolactams, pestalactams A-C (1-3). The structures of 1-3 were determined by analysis of $1 \mathrm{D}$ and 2D NMR, UV, IR, and MS data. The structure of pestalactam A was confirmed following single crystal X-ray diffraction analysis. Pestalactams A-C are the first C-7 alkylated caprolactam natural products to be reported. Pestalactams A (1) and B (2) were tested against two different strains of the malaria parasite Plasmodium falciparum (3D7 and Dd2), and the mammalian cell lines, MCF-7 and NFF, and showed modest in vitro activity in all assays.
\end{abstract}




\section{Introduction}

Over the decades microfungi have been a source of numerous novel, and bioactive secondary metabolites. ${ }^{1,2}$ Although there has recently been a significant increase in research activity on natural products from marine fungi, ${ }^{3-5}$ terrestrial fungi continue to provide natural products chemists with new and/or biologically interesting compounds. Recent examples of terrestrial-derived fungal compounds include the antileishmanial palmarumycins $\mathrm{CP}_{17}$ and $\mathrm{CP}_{18}$, from the endophyte Edenia sp., ${ }^{6}$ the anticancer berkelic acid from Penicillium sp., ${ }^{7}$ farinomalein from Paecilomyces farinosus, ${ }^{8}$ the insecticidal paraherquamides $\mathrm{H}$ and I from Penicillium cluniae, ${ }^{9}$ and the antimalarial polyketide codinaeopsin from the endophytic fungus, Codinaeopsis gonytrichoides. ${ }^{10}$ As part of our research ${ }^{11-15}$ on the chemistry of endophytic fungi from Australian plants we examined the stems of Melaleuca quinquenervia (family Myrtaceae) for its fungal content. Several different microfungal strains were purified and taxonomically identified, including one Pestalotiopsis sp. (BRIP 39872). Chemical investigations of static rice fermentation cultures of this endophytic fungal strain yielded three novel caprolactam derivatives, named pestalactams AC. Herein, the isolation, structure elucidation and preliminary biological evaluations of these novel fungal secondary metabolites are reported.

\section{Results and discussion}

The fungus Pestalotiopsis sp. was grown on damp white rice under static conditions then extracted with EtOAc. This extract was fractionated by $\mathrm{C}_{18}$ flash column chromatography using $\mathrm{H}_{2} \mathrm{O}(0.1 \%$ TFA) and increasing amounts of $\mathrm{MeOH}$ to yield 11 fractions. Fraction 5-7 were combined and further purified by $\mathrm{C}_{18} \mathrm{HPLC}\left[\mathrm{H}_{2} \mathrm{O}(0.1 \%\right.$ TFA)/MeOH)] to yield pestalactams A (1, $19.4 \mathrm{mg}$ ) and $\mathrm{C}(3,2.0 \mathrm{mg})$. Fraction 2 from the flash column was fractionated using $\mathrm{C}_{8} \mathrm{HPLC}$ $\left[\mathrm{H}_{2} \mathrm{O}(0.1 \%\right.$ TFA)/MeCN] to yield pestalactam B (2, $3.0 \mathrm{mg})$.

The major metabolite, pestalactam A (1) was isolated as pale red needles. The (+)LRESIMS of 1 displayed two pseudomolecular ions at m/z 245 and 247 in a relative intensity ratio 
of 3:1, indicating the molecule contained one chlorine atom. The ${ }^{1} \mathrm{H}$ and ${ }^{13} \mathrm{C}$ NMR data (Table 1) in conjunction with the (+)-HRESIMS allowed a molecular formula of $\mathrm{C}_{10} \mathrm{H}_{12} \mathrm{ClNO}_{4}$ to be assigned to 1. The ${ }^{1} \mathrm{H}$ NMR spectrum displayed only six unique resonances, three of which $\left(\delta_{\mathrm{H}} 11.01,10.94\right.$ and 4.98) were determined to be exchangeable following deuterium exchange NMR experiments with $\mathrm{D}_{2} \mathrm{O}$. The remaining protons at $\delta_{\mathrm{H}} 5.95(\mathrm{~s}, 1 \mathrm{H}), 2.56(\mathrm{~s}, 2 \mathrm{H})$ and $1.16(\mathrm{~s}, 6 \mathrm{H})$ were attached to carbons resonating at $\delta_{\mathrm{C}} 108.7,48.3$ and 29.1, respectively, following HSQC data analysis. Nine unique carbons signals, six of which were quarternary, were identified in the ${ }^{13} \mathrm{C} N \mathrm{NR}$ spectrum of 1. Two downfield carbons ( $\delta_{C} 174.9$ and 160.3$)$ were assigned to carbonyl groups and this was supported by strong absorptions in the IR spectrum at 1674 and $1614 \mathrm{~cm}^{-1}$. A gem-dimethyl was established on the basis of a strong HMBC correlation between the protons at $\delta_{\mathrm{H}} 1.16$ and the carbon $\left(\delta_{C} 29.1\right)$ to which they were attached (Figure 2). Furthermore the gem-dimethyl system showed other HMBC correlations to carbons, $\delta_{\mathrm{C}} 149.5$, 48.3 and 69.8. These data combined with the ROESY correlations between the methyl signal at $\delta_{\mathrm{H}} 1.16$ and the methylene unit at $\delta_{\mathrm{H}} 2.56$ and the exchangeable proton at $\delta_{\mathrm{H}} 4.98$, allowed a 2-methylpropan-2-ol substructure to be assigned. The ${ }^{4} J_{\mathrm{CH}} \mathrm{HMBC}$ correlation from the methyl proton at $\delta_{\mathrm{H}} 1.16$ to the carbon at $\delta_{\mathrm{C}} 149.5$ suggested that the $\left(\mathrm{CH}_{3}\right)_{2} \mathrm{COHCH}_{2}-$ moiety was attached to a $\mathrm{sp}^{2}$ carbon substituted by a heteroatom. HMBC correlations from the exchangeable proton at $\delta_{\mathrm{H}} 10.94$ to $\delta_{\mathrm{C}} 48.3$ established that a protonated nitrogen was attached to $\delta_{\mathrm{C}} 149.5$.

The methine singlet at $\delta_{\mathrm{H}} 5.95$ also showed strong HMBC correlations to the methylene carbon $\left(\delta_{C} 48.3\right)$ and the quarternary methine $\left(\delta_{C} 149.5\right)$. At this stage it was determined that the remaining portion of $\mathbf{1}$ consisted of $\mathrm{C}_{4} \mathrm{O}_{3} \mathrm{HCl}$. Although no HMBC correlations were identified from the remaining unassigned exchangeable signal at $\delta_{\mathrm{H}} 11.01$, the protonated nitrogen resonance at $\delta_{\mathrm{H}} 10.94$ showed correlations to $\delta_{\mathrm{C}} 160.3$ and 117.0 , while the methine singlet at $\delta_{\mathrm{H}} 5.95$ showed additional HMBC correlations to $\delta_{\mathrm{C}} 158.4$ and 174.9, thus accounting for all carbon atoms in 1. The weaker HMBC correlations from $\delta_{\mathrm{H}} 5.95$ and $\delta_{\mathrm{H}} 10.94$ to the carbonyls at $\delta_{\mathrm{C}} 174.9$ and 160.3, respectively, suggested that these carbons were only 2 bonds away from each of these protons. A 
strong ${ }^{3} J_{\mathrm{CH}}$ from $\delta_{\mathrm{H}} 10.94$ to the carbon at $\delta_{\mathrm{C}} 117.0$ suggested that this methine might be substituted with the chlorine atom of $\mathbf{1}$. On the basis of a strong $\mathrm{HMBC}$ correlation from $\delta_{\mathrm{H}} 5.95$ to the quarternary carbon at $\delta_{\mathrm{C}} 158.4$, and the fact that the oxygenated exchangeable hydrogen atom $\left(\delta_{\mathrm{H}}\right.$ 11.01) remained unassigned in $\mathbf{1}$, a hydroxyl group was attached to the carbon at $\delta_{\mathrm{C}} 158.4$. Hence the structure of pestalactam A was assigned to 1. An X-ray crystal structure of $\mathbf{1}$ was obtained following refermentation, repurification and crystallization. The ORTEP diagram for $\mathbf{1}$ is shown in Figure 3. The core seven membered ring, the ketone oxygens $\mathrm{O} 2$, O5, the hydroxyl oxygen O4, the chloride $\mathrm{Cl} 3$ and the methylene carbon C8 are all essentially coplanar with torsion angles ranging from 1.0(7) to $-5.9(6)^{\circ}$. The $\left(\mathrm{CH}_{3}\right)_{2} \mathrm{COH}$ group lies out of the plane with the C6-C7-C8-C9 torsion angle $79.5(5)^{\circ}$. The molecules are linked in the crystal lattice through chains of $\mathrm{R}_{2}^{2}(9)$ rings along the $a$ glide axis formed by $\mathrm{N}-\mathrm{H} . . . \mathrm{O}$ and $\mathrm{O}-\mathrm{H} . . . \mathrm{O}$ hydrogen bonds between the N1-H1 amide and the $\mathrm{C} 5=\mathrm{O} 5$ ketone groups and the $\mathrm{O} 4-\mathrm{H} 4$ hydroxy and $\mathrm{C} 2=\mathrm{O} 2$ ketone groups, respectively. The C$\mathrm{C}$ and $\mathrm{N}-\mathrm{C}$ bond lengths within the seven membered ring are all shorter than the expected values for single bonds with C3-C4 1.357(6), C6-C7 1.353(6) Å shorter than C5-C6 1.425(6), C2-C3 1.462(6) and C4-C5 1.495(5) Å while N1-C2 and N1-C7 are 1.378(5) and 1.370(5) Å, respectively.

Pestalactam B (2) was isolated as a pale yellow amorphous solid. The (+)-LRESIMS of 2 displayed a pseudomolecular ion at $m / \mathbf{z} 212$. The $1 \mathrm{D}$ NMR data of $\mathbf{2}$ were very similar to $\mathbf{1}$. The ${ }^{13} \mathrm{C}$ NMR spectra displayed the same number of resonances, the majority of which showed only minor differences in chemical shifts values. The major differences in the two ${ }^{13} \mathrm{C}$ NMR datasets were identified at C-2 $(\Delta=4.4 \mathrm{ppm}), \mathrm{C}-3(\Delta=10.6 \mathrm{ppm}), \mathrm{C}-4(\Delta=1.9 \mathrm{ppm})$ and C-5 $(\Delta=2.8$ ppm) of the caprolactam system. The ${ }^{1} \mathrm{H}$ NMR data readily identified that pestalactam B contained one extra $\mathrm{sp}^{2}$ proton $\left(\delta_{\mathrm{H}} 6.13\right)$ compared with pestalactam A. These data indicated that 2 was the dechloro derivative of $\mathbf{1}$. (+)-HRESIMS and 2D NMR data analysis confirm the structure of 2.

The minor metabolite, pestalactam C (3) was purified as a pale-yellow amorphous solid. Analysis of the (+)-LRESIMS indicated the presence of one chlorine atom in $\mathbf{3}$, based on the isotopic pattern (3:1) of the pseudomolecular ions at $m / z 228$ and 230. The ${ }^{1} \mathrm{H}$ and ${ }^{13} \mathrm{C}$ NMR data in 
conjunction with the (+)-HRESIMS allowed a molecular formula of $\mathrm{C}_{10} \mathrm{H}_{10} \mathrm{ClNO}_{3}$ to be assigned to 3. Comparison of the molecular formula of $\mathbf{3}$ with $\mathbf{1}$ showed that pestalactam $\mathrm{C}$ contained one less oxygen and two less hydrogen atoms, suggesting that $\mathbf{3}$ was the dehydrate derivative of $\mathbf{1}$. Analysis of the ${ }^{13} \mathrm{C}$ NMR spectrum of $\mathbf{3}$ showed that this compound shared 6 similar carbon resonances $(\Delta$ ${ }^{13} \mathrm{C}$ : $0.2-3.3 \mathrm{ppm}$ ) with $\mathbf{1}$, all of which could be assigned to the same chlorinated caprolactam skeleton present in pestalactam A. Furthermore the upfield carbon signals $\left(\delta_{C} 48.3,69.8\right.$ and 29.1) observed in 1 had been replaced with resonances at $\delta_{C}$ 121.0, 149.9, 26.5 and 20.1 in 3 . These data coupled with the ${ }^{1} \mathrm{H}$ NMR spectrum of 3 , which contained an unassigned $\mathrm{sp}^{2}$ proton singlet at $\delta_{\mathrm{H}}$ $6.00(\mathrm{~s}, 1 \mathrm{H})$ and two methyl singlets at $\delta_{\mathrm{H}} 1.87(\mathrm{~s}, 6 \mathrm{H})$, suggested a trisubstituted olefinic moiety was present in 3. ROESY, HMBC, HSQC data analysis confirmed this moiety and linkage of this olefinic unit to the caprolactam system was established via HMBC correlations from $\delta_{\mathrm{H}} 6.01$ to $\delta_{\mathrm{C}}$ 107.5, and from $\delta_{\mathrm{H}} 5.84$ to $\delta_{\mathrm{C}} 121.0$. Hence, pestalactam C was assigned structure 3 .

The pestalactam carbon skeleton is presumably derived from leucine and two malonyl-CoA derived acetates and assembled by a hybrid NRPS-PKS. The proposed linear enzyme-bound thioester intermediate is likely released from the complex as a result of a thioesterase-catalyzed cyclisation. $^{16}$ Oxidation and hydroxylation of the cyclised NRPS-PKS product by cytochrome P450s gives rise to the putative trione intermediate which, on tautomerisation, provides the enol dione 2 . The chlorination of $\mathbf{2}$ to yield the major product $\mathbf{1}$ is most likely catalyzed by a hemedependent chloroperoxidase. $^{17,18}$ The enol dione has been long established as the preferred substrate for chlorination and such fungal enzymes are considered to be the prototypical examples of heme-dependent haloperoxidases. ${ }^{19}$ Subsequent dehydration of the leucine-derived side chain ultimately yields 3 . The assembly of fungal metabolites by hybrid NRPS-PKSs is rare but not unprecedented and several biosynthesis gene clusters have recently been identified including those encoding the biosynthesis of the cytochalasans ${ }^{20}$ and the aspyridones. ${ }^{21}$ We anticipate that future biosynthetic studies including characterisation of the biosynthesis gene cluster will reveal that the pestalactams are indeed NRPS-PKS derived, and that their assembly represents an alternative 
pathway to caprolactam formation and one by which the unique C-7 alkylation can be fully explained.

Prior to submitting pestalactams A-C to the open access compound repository at Eskitis, ${ }^{22}$ and their initial biological evaluation, purity studies were performed using microfluidics liquid chromatography ( $\mu \mathrm{PLC}) .{ }^{23}$ Analysis of the $\mu \mathrm{PLC}$ data and integration of all UV peaks at $254 \mathrm{~nm}$ determined that 1 and 2 had purities of 95\% and 94\%, respectively, while pestalactam C (3) had degraded.

Table 4 shows the in vitro activity of compounds $\mathbf{1}$ and $\mathbf{2}$ against chloroquine resistant (Dd2) and chloroquine sensitive (3D7) P. falciparum malaria parasite lines, and against two mammalian cell types. MCF-7 is a breast adenocarcinoma cancer cell line and NFF (neonatal foreskin fibroblasts) is a "normal" cell type. These cells are routinely used in toxicity studies to determine compound selectivity for parasite or cancer cells. Compound $\mathbf{1}$ and $\mathbf{2}$ displayed similar antimalarial activity, with $\sim 16-41 \%$ parasite growth inhibition achieved at $25 \mu \mathrm{M}$. The compounds were only modestly selective for malaria parasites versus the mammalian cell lines, with both compounds giving $~ 12-64 \%$ inhibition at $100 \mu \mathrm{M}$. The compounds displayed $\sim 3$-fold selectivity for MCF-7 breast cancer cells versus the NFF control cells.

In summary, this paper describes the isolation and structure elucidation of three new caprolactam analogues, pestalactams A-C. Although 55 caprolactam natural products have been reported in the literature to date, ${ }^{24}$ caprolactams with unsaturation between C-3/C-4 and C-6/C-7 are rare, with only four natural products known to contain this functionality. These include silvaticamide (4) from Aspergillus silvaticus, ${ }^{25}$ hygrocin B (5) from Streptomyces hygroscopicus, ${ }^{26}$ and ceratamines A (6) and B (7) from the marine sponge Pseudoceratina sp. ${ }^{27}$

Furthermore, in regards to reported natural product chemistry, compounds 1-3 contain a unique carbon skeleton, due to C-7 alkylation of the caprolactam ring. Pestalactams A and C are the first examples of natural products that contain a halogenated caprolactam ring. 


\section{Experimental section}

\subsection{General Experimental Procedures.}

NMR spectra were recorded at $30{ }^{\circ} \mathrm{C}$ on either a Varian $500 \mathrm{MHz}$ or $600 \mathrm{MHz}$ Unity INOVA spectrometer. The latter spectrometer was equipped with a triple resonance cold probe. The ${ }^{1} \mathrm{H}$ and ${ }^{13} \mathrm{C}$ chemical shifts were referenced to the solvent peak for DMSO- $d_{6}$ at $\delta_{\mathrm{H}} 2.49$ and $\delta_{\mathrm{C}}$ 39.5. LRESIMS were recorded on a Waters ZQ mass spectrometer. HRESIMS were recorded on a Bruker Daltronics Apex III 4.7e fourier-transform mass spectrometer. Melting points were determined using a Gallenkamp digital melting point apparatus and were uncorrected. IR and UV spectra were recorded on a Bruker Tensor 27 spectrometer and a Jasco V650 UV spectrophotometer, respectively. An open glass column (30 mm $\times 40 \mathrm{~mm})$ packed with Alltech Davisil 30-40 um $60 \AA \mathrm{C}_{18}$ bonded silica was used for flash chromatography. A Waters 600 pump equipped with a Waters 996 PDA detector and a Waters 717 autosampler were used for HPLC. A Hypersil C 18 BDS $5 \mu \mathrm{m} 143 \AA$ column $(21.2 \mathrm{~mm} \times 150 \mathrm{~mm})$ and a Hypersil $\mathrm{C}_{8}$ BDS $5 \mu \mathrm{m} 143 \AA$ column $(10 \mathrm{~mm} \times 250 \mathrm{~mm})$ were used for semi-preparative HPLC separations. All solvents used for chromatography, UV, and MS were Lab-Scan HPLC grade, and the $\mathrm{H}_{2} \mathrm{O}$ was Millipore Milli-Q PF filtered. All fungal culture media was purchased from Difco.

\subsection{Collection and Identification of Fungus}

Pestalotiopsis sp. was isolated from a surface sterilised piece of stem ( $2 \mathrm{~mm} \times 10 \mathrm{~mm})$ from the plant Melaleuca quinquenervia collected from Toohey Forest, Queensland, Australia during February of 2003. Sterilisation of the stem fragment was performed by sequential immersion in 95\% EtOH (1 min), 2.1\% NaOCl (5 min) and 95\% EtOH (1 min). The sterilised stem was immediately transferred to a potato dextrose agar (PDA) and incubated at $25{ }^{\circ} \mathrm{C}$ for 3 days. Developing mycelial colonies were subcultured to fresh PDA plates. Colonies of Pestalotiopsis sp. were persistently isolated and one of these cultures was retained (BRIP 39872) for further study. Members of Pestalotiopsis are easily recognised by their distinctive conidial morphology, although 
the determination and delimitation of species in this genus is particularly difficult. ${ }^{28}$ The identification of Pestalotiopsis sp. was based on the presence of acervular conidiomata that produced 4-septate conidia, 22-30 × 6-8 $\mu \mathrm{m}$, with second, third and fourth cells pale to mid-brown; basal and apical cells hyaline, appendages on the apical cells mostly 2, unbranched, up to $20 \mu \mathrm{m}$ long; basal appendage, when present, single, up to $10 \mu \mathrm{m}$ long. A voucher specimen and living cultures were deposited at the Queensland Primary Industries and Fisheries, Plant Pathology Herbarium, Indooroopilly, QLD 4068, Australia.

\subsection{Extraction and Isolation.}

The fungal isolate (BRIP 39872) was initially grown on potato dextrose agar, until a prominent growth of mycelia was achieved. The mycelium covered agar was then cut into $1 \mathrm{~cm}^{3}$ portions, and then transferred to three conical flasks (500 mL) each containing damp white rice (50 g rice plus $100 \mathrm{~mL} \mathrm{H}_{2} \mathrm{O}$ ). The fermentation was allowed to proceed under static conditions at $25{ }^{\circ} \mathrm{C}$ for 28 days after which time the rice and mycelium were extracted with EtOAc $(3 \times 150 \mathrm{~mL})$. The organic extracts were all combined and the solvent removed in vacuo to yield a dark brown gum (3.00 g). This extract was preadsorbed to $\mathrm{C}_{18}$ silica ( 10 g) overnight then loaded onto a $\mathrm{C}_{18}$ open flash column and a 10\% stepwise gradient was performed from $\mathrm{H}_{2} \mathrm{O}(0.1 \%$ TFA) to $\mathrm{MeOH} ; 100$ $\mathrm{mL}$ washes were used for each eluent step. The $10 \% \mathrm{MeOH} / 90 \% \mathrm{H}_{2} \mathrm{O}(0.1 \% \mathrm{TFA})$ fraction (40 mg) was further purified by $\mathrm{C}_{8}$ HPLC using a linear gradient from $100 \% \mathrm{H}_{2} \mathrm{O}(0.1 \%$ TFA) to $50 \%$ $\mathrm{MeCN} / 50 \% \mathrm{H}_{2} \mathrm{O}(0.1 \% \mathrm{TFA})$ in $20 \mathrm{~min}$, followed by another linear gradient to MeCN in 2 min, then isocratic conditions of $\mathrm{MeCN}$ for a further $3 \mathrm{~min}$, all at a flowrate of $4 \mathrm{~mL} / \mathrm{min}$. Pestalactam B (2, $3.0 \mathrm{mg})$ was obtained following lyophilisation of the material eluting between 13-13.5 min. The $20 \% \mathrm{MeOH} / 80 \% \mathrm{H}_{2} \mathrm{O}(0.1 \% \mathrm{TFA})$ and $30 \% \mathrm{MeOH} / 70 \% \mathrm{H}_{2} \mathrm{O}(0.1 \% \mathrm{TFA})$ eluates from the $\mathrm{C}_{18}$

flash column were combined $(81 \mathrm{mg})$ following ${ }^{1} \mathrm{H}$ NMR analysis, and subjected to $\mathrm{C}_{18}$ semipreparative HPLC using a linear gradient from $\mathrm{H}_{2} \mathrm{O}(0.1 \%$ TFA) to $\mathrm{MeOH}$ in 50 min, followed 
by isocratic conditions of $\mathrm{MeOH}$ at a flowrate of $6 \mathrm{~mL} / \mathrm{min}$. This afforded pestalactams A $(\mathbf{1}, 19.4$ $\mathrm{mg})$ and C (3, $2.0 \mathrm{mg})$, which had retention times of 27-29 and 35-36 min, respectively.

\subsection{Pestalactam A (1).}

Pale red needles; mp 175-177 ${ }^{\circ} \mathrm{C}$; UV (MeOH) $\lambda_{\max }(\log \varepsilon) 266$ (4.42), 324 (3.76), 360 (sh, 3.51) nm; IR $v_{\max }(\mathrm{KBr}) 3400-3000,1674,1614,1582,1494,1449,1408,1339,1245,1170,1130$, $1024 \mathrm{~cm}^{-1} ;{ }^{1} \mathrm{H}$ and ${ }^{13} \mathrm{C}$ NMR data (DMSO- $d_{6}$ ) see Table 1; (+)-LRESIMS $\mathrm{m} / \mathrm{z}$ (rel. int.) 246 (100) $[\mathrm{M}+\mathrm{H}]^{+}, 248(33)[\mathrm{M}+\mathrm{H}]^{+} ; \quad(+)$-HRESIMS $\mathrm{m} / \mathrm{z} 246.0517\left(\mathrm{C}_{10} \mathrm{H}_{13}{ }^{35} \mathrm{ClNO}_{4}[\mathrm{M}+\mathrm{H}]^{+}\right.$requires 246.0528).

\subsection{Pestalactam B (2).}

Pale-yellow amorphous solid; UV (MeOH) $\lambda_{\max }(\log \varepsilon) 263$ (4.26), 322 (3.57), 360 (sh, 3.20) nm; IR $v_{\max }(\mathrm{KBr}) 3400-3100,1662,1637,1602,1534,1454,1410,1316,1237,1199,1156$, $1048 \mathrm{~cm}^{-1} ;{ }^{1} \mathrm{H}$ and ${ }^{13} \mathrm{C}$ NMR data (DMSO- $d_{6}$ ) see Table 2; (+)-LRESIMS m/z (rel. int.) 212 (15) $[\mathrm{M}+\mathrm{H}]^{+}, 234(100)[\mathrm{M}+\mathrm{Na}]^{+} ; \quad(+)$-HRESIMS m/z $234.0743\left(\mathrm{C}_{10} \mathrm{H}_{13} \mathrm{NO}_{4} \mathrm{Na}[\mathrm{M}+\mathrm{Na}]^{+}\right.$requires 234.0737).

\subsection{Pestalactam C (3).}

Pale-yellow amorphous solid; UV (MeOH) $\lambda_{\max }$ (log ع) 217 (4.30), 279 (4.41), 327 (4.10), 360 (sh, 3.95) nm; IR $v_{\max }(\mathrm{KBr}) 3400-3100,1688,1659,1407,1204,1021 \mathrm{~cm}^{-1} ;{ }^{1} \mathrm{H}$ and ${ }^{13} \mathrm{C}$ NMR data (DMSO- $d_{6}$ ) see Table 3; (+)-LRESIMS m/z (rel. int.) 245 (100) $[\mathrm{M}+\mathrm{H}]^{+}, 247$ (33) [M+H] $]^{+}$, $250(100)[\mathrm{M}+\mathrm{Na}]^{+}, 252(33)[\mathrm{M}+\mathrm{Na}]^{+} ;(+)$-HRESIMS m/z $250.0244\left(\mathrm{C}_{10} \mathrm{H}_{10} \mathrm{ClNO}_{3} \mathrm{Na}[\mathrm{M}+\mathrm{Na}]^{+}\right.$ requires 250.0241).

\subsection{X-ray crystallography data for pestalactam A (1)}


X-ray diffraction data for 1 were measured at 295(2) K using a Rigaku AFC7R four circle diffractometer ( $\omega$-2 $\theta$ scan mode, graphite monochromated Mo- $\mathrm{K}_{\mathrm{a}}$ radiation $\mathrm{l}=0.71069 \AA$ ). The structure was solved by direct methods and refined by full matrix least squares refinement on $F^{2}$. Anisotropic thermal parameters were refined for non-hydrogen atoms. The peripheral carbon and oxygen atoms of the $\left(\mathrm{CH}_{3}\right)_{2} \mathrm{OH}$ group showed high thermal motion reflective of a degree of disorder in this group. The carbon protons were included at calculated positions and constrained as riding atoms with C-H $0.95 \AA$ A. The hydroxyl protons in $\mathbf{1}$ was located from difference Fourier maps and constrained as riding atoms with $\mathrm{O}-\mathrm{H} 0.85 \AA$. $\mathrm{U}_{\mathrm{iso}}(\mathrm{H})$ values were set to $1.2 \mathrm{U}_{\mathrm{eq}}$ on the parent atom. Weights derivative of $w=1 /\left[\mathrm{s}^{2}(F)\right]$ were employed. Neutral atom complex scattering factors were employed. Computation used the TeXsan ${ }^{29}$ and SHELX-97 ${ }^{30}$ program systems and ORTEP-3 $3^{31}$ and PLATON ${ }^{32}$ software. Crystallographic data for the structure reported in this paper have been deposited at the Cambridge Crystallographic Data Centre (CCDC No. 748402). Copies of the data can be obtained, free of charge, on application to the Director, CCDC, 12 Union Road, Cambridge CB2 1EZ, UK (Fax: +44-1223-336033; email:

Crystal Data. $\mathrm{C}_{10} \mathrm{H}_{12} \mathrm{ClNO}_{4} M=245.7$, monoclinic, space group $P 21 / \mathrm{a}, a=14.466(4), b=$ 6.563(2), $c=12.390(4) \AA, \beta=111.88(2)^{\mathrm{O}}, U=1091.5(6) \AA^{3}, Z=4, D_{\mathrm{C}}=1.49 \mathrm{~g} \mathrm{~cm}^{-3}, \mu=0.35 \mathrm{~mm}^{-}$ 1 , Crystal size: $0.55 \times 0.15 \times 0.15 \mathrm{~mm}, 2152$ reflections collected, 1919 unique $\left(\mathrm{R}_{\mathrm{int}}=0.037\right), R=$ 0.063 [1380 reflections with $\left.\mathrm{I}>2 \mathrm{~s}(\mathrm{I})], \mathrm{w} R F^{2}\right)=0.182$ (all data).

\subsection{P. falciparum growth inhibition assays.}

In vitro antimalarial growth inhibition assays were carried out using P. falciparum lines 3D7 (chloroquine-sensitive) and Dd2 (chloroquine-resistant), as previously described. ${ }^{33-35}$ Briefly, synchronous ring-stage infected erythrocytes (0. 5\% parasitemia and $2.5 \%$ hematocrit) were incubated in triplicate wells of 96 well culture dishes with different concentrations of compound for 
48 hours before adding $0.5 \mu \mathrm{Ci}\left[{ }^{3} \mathrm{H}\right]$-hypoxanthine. After incubating for a further 16-24 hours, cultures were harvested onto 1450 MicroBeta filter mats (Wallac) and ${ }^{3} \mathrm{H}$ incorporation determined using a 1450 MicroBeta liquid scintillation counter. Percentage inhibition compared to matched DMSO controls $(0.5 \%)$ was determined and $\mathrm{IC}_{50}$ values calculated using linear interpolation of inhibition curves. ${ }^{36}$ Three independent experiments were carried out and the mean $\mathrm{IC}_{50}( \pm \mathrm{SD})$ is shown in Table 4.

\subsection{Mammalian Cell Assays.}

All cell lines were cultured in 10\% heat-inactivated foetal calf serum (CSL, Australia) in RPMI 1640 medium supplemented with $100 \mathrm{U} / \mathrm{mL}$ penicillin, $100 \mu \mathrm{g} / \mathrm{mL}$ streptomycin, and $3 \mathrm{mM}$ HEPES at $5 \% \mathrm{CO}_{2}, 99 \%$ humidity at $37{ }^{\circ} \mathrm{C}$. Routine mycoplasma tests were performed using Hoechst stain and were always negative. Cytotoxicities of compounds were determined by clonogenic survival of MCF-7 (breast adenocarcinoma) and human neonatal foreskin fibroblasts (NFF) cells. ${ }^{37,38}$ Cells were plated into 96-well microtitre plates at $5 \times 10^{3}$ cells / well, and allowed to adhere overnight. Compounds were added to culture medium at the indicated final concentrations, and plates incubated in the above conditions for 96 hours. Cell survival was then assayed using sulforhodamine B (SRB; Sigma, St. Louis, MO). Briefly, the culture medium was removed from the 96-well microtitre plates and the plates washed twice with phosphate buffered saline (PBS), before the cells were fixed with methylated spirits for $15 \mathrm{~min}$. The plates were then rinsed with tap water and the fixed cells stained with $50 \mu \mathrm{L} /$ well of SRB solution $(0.4 \%$ sulforhodamine B (w/v) in 1\% (v/v) acetic acid) over a period of 1 hour. The SRB solution was removed from the wells and the plates rapidly washed two times with $1 \%$ (v/v) acetic acid. Protein bound dye was then solubilised with the addition of $100 \mu \mathrm{L}$ of $10 \mathrm{mM}$ unbuffered Tris, and incubated for $15 \mathrm{~min}$ at $25^{\circ} \mathrm{C}$. Plates were then read at $564 \mathrm{~nm}$ on a VERSA max tuneable microplate reader (Molecular Devices, Sunnyvale, CA). Data is taken from a minimum of triplicate 
in at least 2 separate experiments, and expressed as percentage inhibition from cells treated with vehicle alone.

\section{Acknowledgments}

The authors thank Bob Coutts (Griffith University) for assistance with plant identification, and Hoan The Vu (Griffith University) for HRESIMS measurements.

\section{Supplementary data}

${ }^{1} \mathrm{H}$ and ${ }^{13} \mathrm{C}$ NMR data for pestalactams A-C (1-3). Supplementary data associated with this article can be found, in the online version at doi:

\section{References and notes.}

1. W. B. Turner, Fungal Metabolites, 1971.

2. W. B. Turner and D. C. Aldridge, Fungal Metabolites II, Academic Press, London, New York, 1983.

3. A. Piorko, Fungi, 2007, 208-235.

4. M. Saleem, M. S. Ali, S. Hussain, A. Jabbar, M. Ashraf and Y. S. Lee, Nat. Prod. Rep., 2007, 24, 1142-1152.

5. T. S. Bugni and C. M. Ireland, Nat. Prod. Rep., 2004, 21, 143-163.

6. S. Martinez-Luis, G. Della-Togna, P. D. Coley, T. A. Kursar, W. H. Gerwick and L. Cubilla-Rios, J Nat Prod, 2008, 71, 2011-2014.

7. $\quad$ A. Stierle Andrea, B. Stierle Donald and K. Kelly, J. Org. Chem., 2006, 71, 5357-5360.

8. $\quad$ S. P. Putri, H. Kinoshita, F. Ihara, Y. Igarashi and T. Nihira, J Nat Prod, 2009, 72, 1544-1546.

9. M. P. Lopez-Gresa, M. C. Gonzalez, L. Ciavatta, I. Ayala, P. Moya and J. Primo, J. Agric. Food Chem., 2006, 54, 2921-2925.

10. R. Kontnik and J. Clardy, Org Lett, 2008, 10, 4149-4151.

11. R. A. Davis, J. Nat. Prod., 2005, 68, 769-772.

12. R. A. Davis, V. Andjic, M. Kotiw and R. G. Shivas, Phytochemistry, 2005, 66, 2771-2775.

13. R. A. Davis, J. Longden, V. M. Avery and P. C. Healy, Bioorg. Med. Chem. Lett., 2008, 18, 2836-2839.

14. R. A. Davis, D. Watters and P. C. Healy, Tetrahedron Letts., 2005, 46, 919-921.

15. P. C. Healy, A. Hocking, N. Tran-Dinh, J. I. Pitt, R. G. Shivas, J. K. Mitchell, M. Kotiw and R. A. Davis, Phytochemistry, 2004, 65, 2373-2378.

16. S. A. Sieber and M. A. Marahiel, Chem Rev, 2005, 105, 715-738.

17. $\quad$ L. P. Hager, D. R. Morris, F. S. Brown and H. Eberwein, J Biol Chem, 1966, 241, 1769-1777.

18. D. R. Morris and L. P. Hager, J Biol Chem, 1966, 241, 1763-1768.

19. F. H. Vaillancourt, E. Yeh, D. A. Vosburg, S. Garneau-Tsodikova and C. T. Walsh, Chem Rev, 2006, 106, 3364-3378.

20. J. Schumann and C. Hertweck, J Am Chem Soc, 2007, 129, 9564-9565.

21. S. Bergmann, J. Schumann, K. Scherlach, C. Lange, A. A. Brakhage and C. Hertweck, Nat Chem Biol, 2007, 3, 213-217.

22. http://www.griffith.edu.au/science/queensland-compound-library

23. G. K. Pierens, A. R. Carroll, R. A. Davis, M. E. Palframan and R. J. Quinn, J. Nat. Prod., 2008, 71, 810-813.

24. Dictionary of Natural Products on CD-Rom, Chapman and Hall / CRC Press, London, UK, 2009, vol. 18.1.

25. M. Yamazaki, H. Fujimoto, Y. Ohta, Y. Iitaka and A. Itai, Heterocycles, 1981, 15, 889-893.

26. P. Cai, F. Kong, M. E. Ruppen, G. Glasier and G. T. Carter, J Nat Prod, 2005, 68, 1736-1742.

27. E. Manzo, R. van Soest, L. Matainaho, M. Roberge and R. J. Andersen, Org Lett, 2003, 5, 4591-4594. 
28. R. Jeewon, E. C. Liew, J. A. Simpson, I. J. Hodgkiss and K. D. Hyde, Mol Phylogenet Evol, 2003, 27, 372383.

29. TeXsan for Windows, Version 1.06. MSC 9009 New Trails Drive, The Woodlands, TX 77381, USA, 19972001.

30. G. M. Sheldrick, Acta Crystallogr A, 2008, 64, 112-122.

31. $\quad$ L. J. Farrugia, J. Appl. Cryst., 1997, 30, 565.

32. A. L. Spek, Acta Crystallogr D Biol Crystallogr, 2009, 65, 148-155.

33. K. T. Andrews, T. N. Tran, A. J. Lucke, P. Kahnberg, G. T. Le, G. M. Boyle, D. L. Gardiner, T. S. SkinnerAdams and D. P. Fairlie, Antimicrob Agents Chemother, 2008, 52, 1454-1461.

34. G. S. Dow, Y. Chen, K. T. Andrews, D. Caridha, L. Gerena, M. Gettayacamin, J. Johnson, Q. Li, V. Melendez, N. Obaldia, 3rd, T. N. Tran and A. P. Kozikowski, Antimicrob Agents Chemother, 2008, 52, 3467-3477.

35. D. Walliker, I. A. Quakyi, T. E. Wellems, T. F. McCutchan, A. Szarfman, W. T. London, L. M. Corcoran, T. R. Burkot and R. Carter, Science, 1987, 236, 1661-1666.

36. W. Huber and J. C. Koella, Acta Trop, 1993, 55, 257-261.

37. S. M. Ogbourne, A. Suhrbier, B. Jones, S. J. Cozzi, G. M. Boyle, M. Morris, D. McAlpine, J. Johns, T. M. Scott, K. P. Sutherland, J. M. Gardner, T. T. Le, A. Lenarczyk, J. H. Aylward and P. G. Parsons, Cancer Res, 2004, 64, 2833-2839.

38. S. J. Cozzi, P. G. Parsons, S. M. Ogbourne, J. Pedley and G. M. Boyle, Cancer Res, 2006, 66, $10083-10091$. 


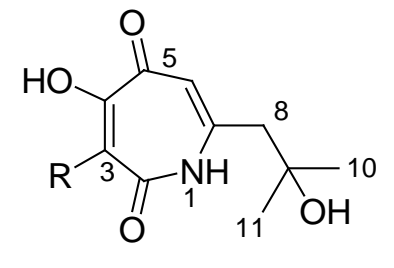

Pestalactam A (1) $\mathrm{R}=\mathrm{Cl}$ Pestalactam B (2) $\mathrm{R}=\mathrm{H}$

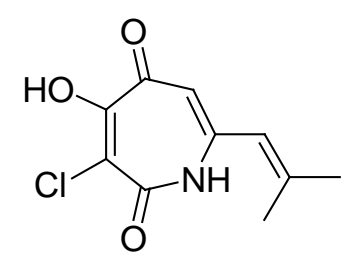

Pestalactam C (3)

Figure 1. Chemical structures for pestalactams A-C (1-3).

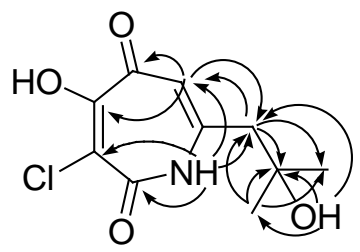<smiles>O=c1cc(CCC2(O)CC2)[nH]c(=O)c(Cl)c1O</smiles>

Figure 2. Key HMBC $(\rightarrow)$ and ROESY $(\leftrightarrow)$ correlations for 1 .

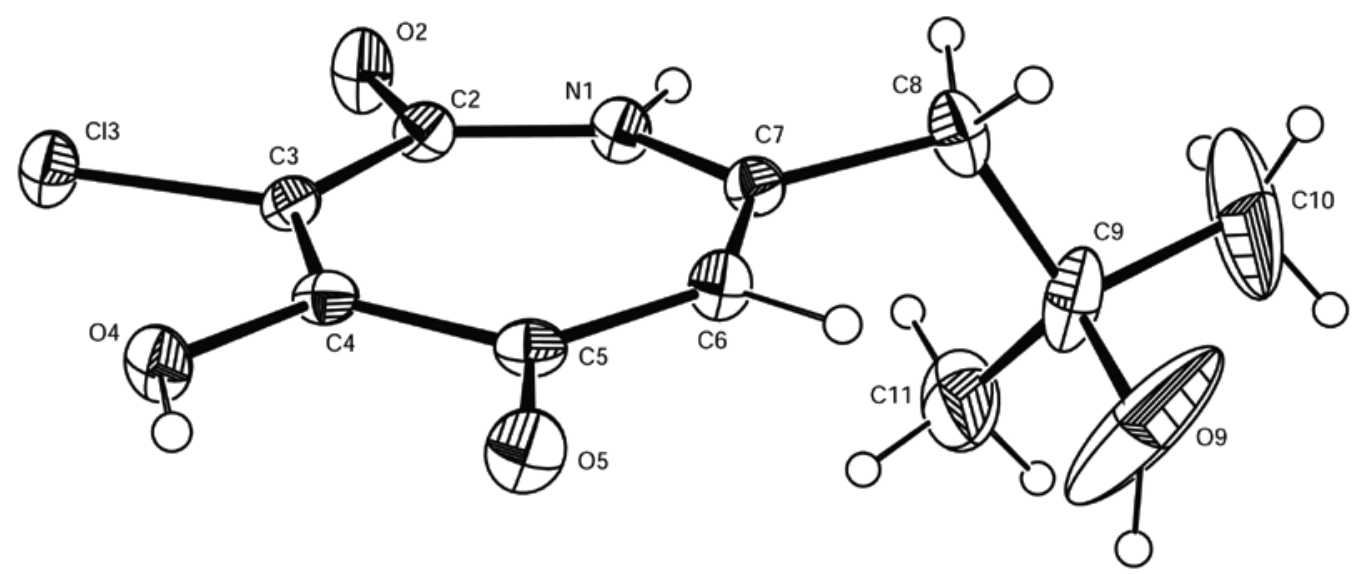

Figure 3. ORTEP Diagram for Pestalactam A (1). 


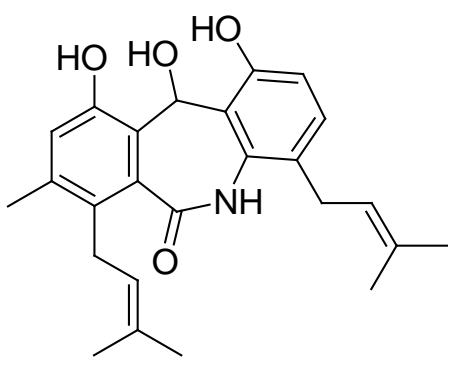

Silvaticamide (4)

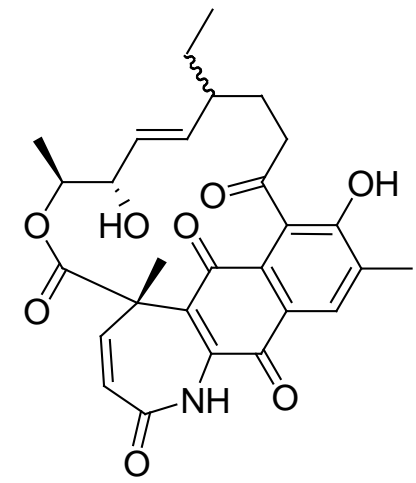

Hygrocin B (5)

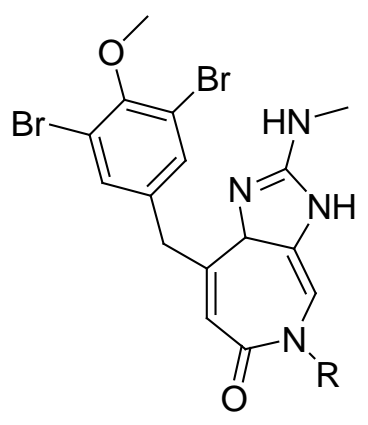

Ceratamine A (6) $\mathrm{R}=\mathrm{Me}$ Ceratamine $B(7) \mathrm{R}=\mathrm{H}$

Figure 4. Caprolactam natural products 4-7.

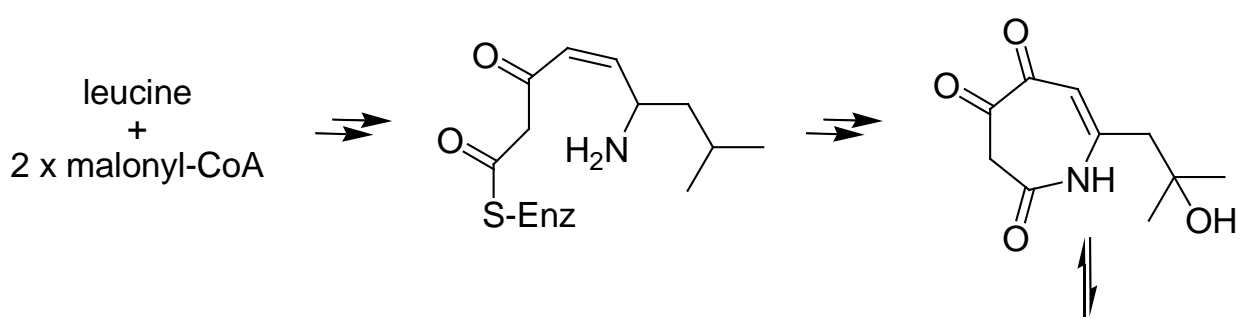<smiles>CC(C)=Cc1cc(=O)c(O)c(Cl)c(=O)[nH]1</smiles>

3<smiles>CC(C)(O)Cc1cc(=O)c(O)c(Cl)c(=O)[nH]1</smiles>

1<smiles>CC(C)(O)Cc1cc(=O)c(O)cc(=O)[nH]1</smiles>

2

Scheme 1. Proposed Biogenesis of Pestalactams A-C (1-3). 
Table 1. NMR Data for Pestalactam A (1). ${ }^{a}$

\begin{tabular}{|c|c|c|c|c|c|}
\hline position & ${ }^{13} \mathrm{C}$ & ${ }^{1} \mathrm{H}$ (mult., $J$ in $\mathrm{Hz}$, int.) & gCOSY & gHMBC & ROESY \\
\hline 1 & & 10.94 (brs, $1 \mathrm{H})$ & 6 & $2,3,6,8$ & \\
\hline 2 & 160.3 & & & & \\
\hline 3 & 117.0 & & & & \\
\hline 4 & 158.4 & & & & \\
\hline $4-\mathrm{OH}$ & & 11.01(brs, $1 \mathrm{H})$ & & & \\
\hline 5 & 174.9 & & & & \\
\hline 6 & 108.7 & $5.95(\mathrm{~s}, 1 \mathrm{H})$ & 1,8 & $4,5,7,8,9$ & 8,10 \\
\hline 7 & 149.5 & & & & \\
\hline 8 & 48.3 & $2.56(\mathrm{~s}, 2 \mathrm{H})$ & 6, 9-OH, 10 & $2,5,6,7,9,10$ & 6, 9-OH, 10 \\
\hline 9 & 69.8 & & & & \\
\hline 9-OH & & 4.98 (brs, $1 \mathrm{H})$ & 8 & $8,9,10$ & 8,10 \\
\hline 10 & 29.1 & $1.16(\mathrm{~s}, 3 \mathrm{H})$ & 8 & $7,8,9,10$ & $6,8,9-\mathrm{OH}$ \\
\hline 11 & 29.1 & $1.16(\mathrm{~s}, 3 \mathrm{H})$ & 8 & $7,8,9,10$ & $6,8,9-\mathrm{OH}$ \\
\hline
\end{tabular}

${ }^{a}$ Spectra were recorded in DMSO- $d_{6}$ at $30{ }^{\circ} \mathrm{C}$. 
Table 2. NMR Data for Pestalactam B (2). ${ }^{a}$

\begin{tabular}{|c|c|c|c|c|c|}
\hline position & ${ }^{13} \mathrm{C}$ & ${ }^{1} \mathrm{H}$ (mult., $J$ in $\mathrm{Hz}$, int.) & gCOSY & gHMBC & ROESY \\
\hline 1 & & 10.50 (brs, 1H) & 3,6 & & 8 \\
\hline 2 & 164.7 & & & & \\
\hline 3 & 106.4 & $6.13(\mathrm{~d}, 0.8,1 \mathrm{H})$ & 1 & $2,4,5$ & \\
\hline 4 & 160.3 & & & & \\
\hline $4-\mathrm{OH}$ & & 10.30 (brs, $1 \mathrm{H})$ & & & \\
\hline 5 & 177.7 & & & & \\
\hline 6 & 109.1 & $5.84(\mathrm{~d}, 1.2,1 \mathrm{H})$ & 1 & $4,5,7,8$ & 8,10 \\
\hline 7 & 150.3 & & & & \\
\hline 8 & 48.5 & $2.52(\mathrm{~s}, 2 \mathrm{H})$ & 9-OH, 10 & $6,7,9,10$ & 1, 6, 9-OH, 10 \\
\hline 9 & 69.7 & & & & \\
\hline 9-OH & & 4.98 (brs, 1H) & & $8,9,10$ & 8,10 \\
\hline 10 & 29.1 & $1.15(\mathrm{~s}, 3 \mathrm{H})$ & 8 & $8,9,10$ & $6,8,9-\mathrm{OH}$ \\
\hline 11 & 29.1 & $1.15(\mathrm{~s}, 3 \mathrm{H})$ & 8 & $8,9,10$ & $6,8,9-\mathrm{OH}$ \\
\hline
\end{tabular}

${ }^{a}$ Spectra were recorded in DMSO- $d_{6}$ at $30{ }^{\circ} \mathrm{C}$. 
Table 3. NMR Data for Pestalactam C (3). ${ }^{a}$

\begin{tabular}{llllll}
\hline position & ${ }^{13} \mathrm{C}$ & ${ }^{1} \mathrm{H}$ (mult., $J$, int.) & gCOSY & gHMBC & ROESY \\
\hline 1 & & 11.26 (brs, 1H) & 6 & 3 & 8 \\
2 & 160.6 & & & & \\
3 & 117.2 & & & & \\
4 & 158.1 & & & \\
$4-\mathrm{OH}$ & & 11.00 (brs, 1H) & & \\
5 & 175.1 & & & $4,5,7,8$ & 11 \\
6 & 107.5 & $5.84(\mathrm{~s}, 1 \mathrm{H})$ & 1 & & \\
7 & 146.2 & & & $6,10,11$ & 1,10 \\
8 & 121.0 & $6.01(\mathrm{~s}, 1 \mathrm{H})$ & 10,11 & & \\
9 & 149.8 & & & $8,9,11$ & 8, \\
10 & 26.5 & $1.87(\mathrm{~s}, 3 \mathrm{H})$ & 8 & $8,9,10$ & 6 \\
11 & 20.1 & $1.87(\mathrm{~s}, 3 \mathrm{H})$ & 8 & & \\
\hline
\end{tabular}

${ }^{a}$ Spectra were recorded in DMSO- $d_{6}$ at $30^{\circ} \mathrm{C}$. 
Table 4. In vitro activity of compounds $\mathbf{1}$ and $\mathbf{2}$ against malaria parasites and mammalian cells

\begin{tabular}{|c|c|c|c|c|}
\hline \multirow[t]{2}{*}{ Compound } & \multicolumn{2}{|c|}{$\begin{array}{c}P . \text { falciparum } \\
\text { (\% inhibition at } 25 \mu \mathrm{M})\end{array}$} & \multicolumn{2}{|c|}{$\begin{array}{c}\text { Mammalian cells } \\
\text { (\% inhibition at } 100 \mu \mathrm{M})\end{array}$} \\
\hline & Dd2 & 3D7 & MCF-7 & NFF \\
\hline 1 & $41.3( \pm 5.0)$ & $16.2( \pm 7.6)$ & $64.4( \pm 3.0)$ & $20.2( \pm 9.2)$ \\
\hline 2 & $36.3( \pm 3.2)$ & $20.7( \pm 5.1)$ & $58.5( \pm 3.2)$ & $12.8( \pm 4.2)$ \\
\hline Chloroquine & $2.17( \pm 1.3)$ & $0.02( \pm 0.01)$ & - & - \\
\hline
\end{tabular}


Pestalactams A-C: Novel Caprolactams from the Endophytic Fungus Pestalotiopsis sp.

Rohan A. Davis, ${ }^{\mathrm{a}, *}$ Anthony R. Carroll, ${ }^{\mathrm{a}}$ Katherine T. Andrews, ${ }^{\mathrm{a}, \mathrm{b}}$ Glen M. Boyle, ${ }^{\mathrm{b}}$ Truc Linh Tran, ${ }^{\mathrm{b}}$ Peter C. Healy, John A. Kalaitzis, ${ }^{\mathrm{d}}$ and Roger G. Shivas ${ }^{\mathrm{e}}$

a Eskitis Institute, Griffith University, Brisbane, QLD 4111, Australia

b Queensland Institute for Medical Research, Herston, Queensland, Australia, 4006; Griffith Medical Research College, a joint program of Griffith University and QIMR, Herston, Queensland, Australia

c School of Biotechnology and Biomolecular Sciences, The University of New South Wales, Sydney, NSW 2052, Australia d Queensland Primary Industries and Fisheries, Indooroopilly, QLD 4068, Australia
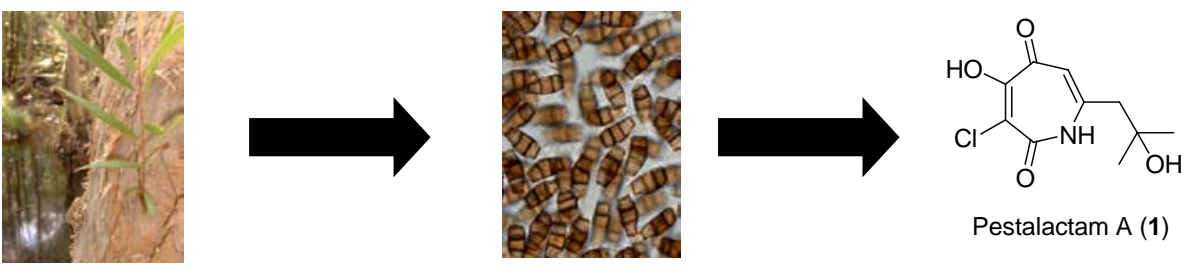

Pestalactam A (1) 
